\section{Glück im Lateinischen}

Im Lateinischen kristallisieren sich zur Umschreibung des Glücks drei Begriffe heraus. Entgegen der ansonsten zu beobachtenden Latinisierung von Konzepten der griechischen Philosophie, finden sich keine Versuche für eudaimonia ein lateinisches Äquivalent auszubilden. Beatus und davon abgeleitet beatitudo sind von unsicherer etymologischer Herkunft und bezeichnen in ihrer ursprünglichen Bedeutung den Zustand, mit Glücksgütern gesegnet und beschenkt zu sein (Walde/Hofmann 1938, 101). Felix und davon abgeleitet felicitas sind vermutlich auf fèlāre, fēcundus bzw. fêtus zurückzuführen und führen damit in ursprüngliche Bedeutungskonnotationen wie `säugen ‘, ১befruchtet`, strächtig` (474f.). Inhaltlich ist es also im Wesentlichen das Phänomen der Fruchtbarkeit, das mit dem Glück assoziiert wird. Drittens verselbständigt sich die mythologische Bezeichnung der Göttin Fortuna, das lateinische Äquivalent zur griechischen Göttin Tyche, zum eigenständigen Begriff für Glück. Im Lateinischen wird damit die Bedeutung des Zufallsglücks auf der sprachlichen Ebene in einen eigenen Rang erhoben. Die romanischen Sprachen folgen darin ihren lateinischen Wurzeln. Das Deutsche kennt bekanntlich diese Unterscheidung nicht und verwendet den Begriff ` Glück ‘ äquivok für die Gunst des Zufalls einerseits und das Glück als inneren Zustand bzw. Resultat menschlicher Bemühung. Diese Bedeutungsebenen decken im Lateinischen die Begriffe beatitudo und felicitas ab. Beide Begriffe können synonym verwendet werden, jedoch setzt sich felicitas als Übersetzungswort für das griechische eudaimonia durch (vgl. Spaemann 1974, 691).

Dieser Umstand hat Autoren der lateinischen Christenheit dazu motiviert, die sprachliche Unterscheidung in ein von Gott geschenktes einerseits und ein heidnisches Glück andererseits, wie sie sich in der jüdisch-christlichen Verwendung von makarioi und eudaimonia findet, auch im Lateinischen abzubilden. Wenngleich die Unterscheidung nicht mit der gleichen Strenge wie im Griechischen durchgeführt wird, zeichnet sich mehr und mehr vor allem im mittelalterlichen Sprachgebrauch ab, beatitudo zur Bezeichnung des wahren und ewigen christlichen Glücks heranzuziehen, während felicitas eher für das heidnische, irdische Glück steht. In Rechnung zu stellen ist die damit offensichtlich durchaus auch mitbeabsichtigte Abgrenzung vom Konzept des antiken Eudämonismus. Freilich ist hier Vorsicht vor einer allzu pauschalen Anwendung dieser Unterscheidung geboten. Thomas von Aquin beispielsweise entfaltet seine bemerkenswerte und folgenreiche Glückslehre unter dem Begriff der beatitudo und bemüht sich dennoch um einen Ausgleich mit Aristoteles. Wenn Autoren der Renaissance wie Marsilio Ficino und andere in ihren lateinischen Traktaten über das Glück ausdrücklich auf den Begriff der felicitas zurückgreifen, so ist dies durchaus auch ein sprachlicher Indikator für den Versuch, das christliche Glück mit dem antiken Eudämonismus zu versöhnen.

\section{Literatur}

Spaemann, Robert: Glück, Glückseligkeit. In: Joachim Ritter u.a. (Hg.): Historisches Wörterbuch der Philosophie. Bd. 3. Darmstadt 1974, 679-707.

Walde, Alois/Hofmann, Johann Baptist: Lateinisches Etymologisches Wörterbuch. 3., neubearb. Auflage von J.B. Hofmann. Heidelberg 1938.

Jörg Lauster 